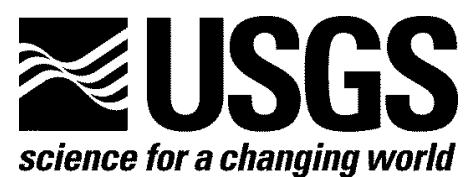

\title{
C-Language Software for Computing Strong Ground Motion Metrics and Seismograph Self Noise
}

By J. R. Evans, R. L. Nigbor, and C. R. Hutt

Open-file Report 2006-1369

U.S. Department of the Interior

U.S. Geological Survey 


\title{
U.S. Department of the Interior \\ DIRK KEMPTHORNE, Secretary
}

\author{
U.S. Geological Survey \\ Mark Myers, Director
}

U.S. Geological Survey, Reston, Virginia 2006

For product and ordering information:

World Wide Web: http://www.usgs.gov/pubprod

Telephone: 1-888-ASK-USGS

For more information on the USGS - the Federal source for science about the Earth, its natural and living resources, natural hazards, and the environment:

World Wide Web: http://www.usgs.gov

Telephone: 1-888-ASK-USGS

Suggested citation:

Evans, J. R., Nigbor, R. L., and Hutt, C. R., 2006, C-Language software for computing strong ground motion metrics and self noise: Menlo Park CA, U.S. Geological Survey, Open-file Report, 20061369

Any use of trade, product, or firm names is for descriptive purposes only and does not imply endorsement by the U.S. Government.

Although this report is in the public domain, permission must be secured from the individual copyright owners to reproduce any copyrighted material contained within this report. 


\section{Contents}

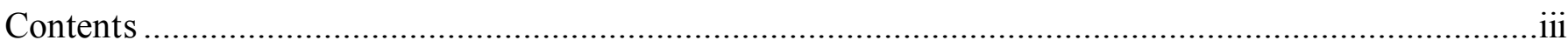

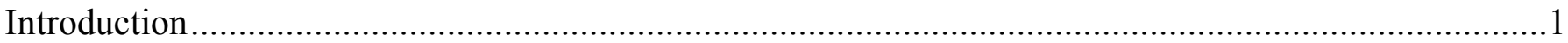

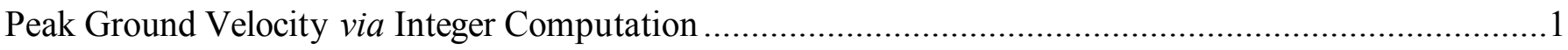

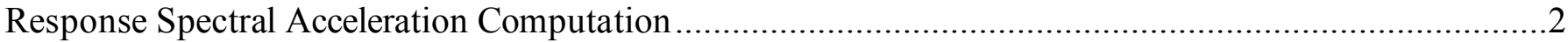

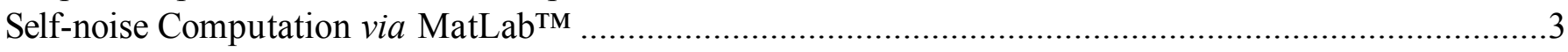

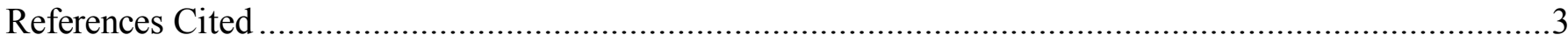




\section{C-Language Software for Computing Strong Ground Motion Metrics and Seismograph Self Noise}

By J. R. Evans ${ }^{1}$, R. L. Nigbor ${ }^{2}$, and C. R. Hutt ${ }^{3}$

\section{Introduction}

This Open-file Report releases several software modules for public use. No warrantees, implied or explicit, are given for this software.

The software modules are (1) C-language integer code for approximate, rapid computation of peak ground velocity (PGV) starting from an integer accelerogram (digitizer counts) and using integer arithmetic with no multiply or divide operations, (2) C-language double-precision code (and an example of integer code for part of this computation) for computing the response spectral acceleration and related ground-motion metrics $\left(S_{a}, S_{v}, S_{d}, P S V\right)$ of an accelerogram (provided in units of $\mathrm{cm} / \mathrm{s}^{2}$ ) by the method of Nigam and Jennings (1969), and (3) a MatLab (Version 7.1) ".m" script for computing instrument self-noise from a long recording of the self noise of (a) a recorder with shorted inputs or, (b) a complete seismographic system at a location with ambient seismic ground seismic noise well below instrument self noise. The latter, if the self noise of the recorder is lower or is subtracted, represents the self noise of the seismic sensor.

Test examples are provided for each routine so that users can verify their implementations of this software. The software and supporting files are available at http://pubs.usgs.gov/of/2006/1369/.

\section{Peak Ground Velocity via Integer Computation}

Peak Ground Velocity (PGV) is an important metric for strong ground motions, relating reliably to the structural damage potential from such shaking. PGV can also be used to determine the relative importance ("size") of various records when storage is low in a field instrument and it is desired to delete the "smallest" events, making room for a record with stronger shaking. In the latter application, PGV is a more reliable metric than PGA (Peak Ground Velocity).

This PGV computation is implemented in integer arithmetic, without multiplication or division, to maximize execution speed in resource-limited accelerographs. To perform the firmware computation efficiently, all necessary coefficients should first be computed and converted to integer, often in a laboratory workstation, and then hard coded into this routine ("pgv.c"). Thus, this algorithm currently is limited to 50, 100, and 200 sps input data. However, other sampling

\footnotetext{
${ }^{1}$ U.S. Geological Survey, 345 Middlefield Rd, MS-977, Menlo Park CA 94025-3591, jrevans@usgs.gov.

${ }^{2}$ Univ. of California at Los Angeles, Dept. of Civil Engineering, Boelter Hall 5731, Los Angeles CA 90095-1593, nigbor@ucla.edu.

${ }^{3}$ U.S. Geological Survey, Albuquerque Seismological Laboratory, P.O. Box 82010, Albuquerque NM 87117, bhutt@usgs.gov.
} 
rates can be arranged by following these examples with some care (see comments in the source code).

The input accelerogram is first filtered by a high-pass order-one causal Butterworth with its corner at $0.2 \mathrm{~Hz}$. The filtered acceleration trace is then integrated to velocity by simple summation. The filtering is a reliable, simple method for reducing long-period artifacts in the computed velocity trace. The filtering is implemented as a series of binary shifts and sums and is therefore very fast. One white-noise bit is added to the acceleration signal to stabilize the result against baseline errors and quantization.

In the test examples provided, the mean error compared to a double-precision computation is about $-8 \%$ and ranges from -18 to $-2 \%$. Accuracy is not significantly better using only events which do not cause large long-period oscillations in the velocity trace (of these "better" records, the mean error is about $-7 \%$ and the range similar to the whole set). Therefore, this degree of error must be tolerated by other components in any system implementing this code. For example, in selecting events to delete in order to make space for a larger event, this degree of inaccuracy probably is acceptable since only rather small (less useful) records are likely to be deleted. In preliminary ShakeMap computations, other sources of error are much larger, so this algorithm is acceptable if followed by recomputation in the laboratory from the processed accelerogram.

MatLab ${ }^{\mathrm{TM}}$ scripts to aid testing of this software are included.

The software and supporting data and scripts are in the subdirectory named "PeakGroundVelocity".

\section{Response Spectral Acceleration Computation}

For many purposes, including earthquake engineering and supporting emergency responders (e.g., ShakeMap and HAZUS) the response spectral acceleration $\left(S_{a}\right)$ and related metrics of the accelerogram (PGA and PGV) must be computed. Here we provide double-precision software applying the method of Nigam and Jennings (1969), a widely used technique. (Please note that at long periods this computation is prone to round-off error if not performed in double-precision arithmetic.) This software module ("rsc.c") has been tested against a previous, widely used implementation of the Nigam and Jennings algorithm ("BAP"; Converse and Brady, 1992) and is believed to produce authoritative values.

As an example of an integer computation yielding response spectral values, we also offer "psv_c()" and its associated codes. Unfortunately, this code does not, as written, yield response spectral acceleration $\left(S_{a}\right)$ and would therefore need to be modified and tested for use with ShakeMap, for example. This integer implementation currently yields only response spectral displacement $\left(S_{d}\right)$ and "pseudovelocity" values $\left(\omega S_{d}\right.$; "PSV"). In five test examples we explored (and include here for the user) we obtained errors relative to "rsc.c" results for these two metrics, $S_{d}$ and $\omega S_{d}$, of 7.83 and $2.45 \%, 1.85$ and $0.69 \%, 5.11$ and $0.43 \%, 11.37$ and $11.40 \%$, and 3.27 and $0.41 \%$ error - a range similar to that of "pgv.c". These errors are acceptable for preliminary ShakeMap computations but not for final ShakeMaps. That is, an integer implementation is likely to be acceptable in field instruments reporting back to a laboratory, as long as the waveforms also follow quickly and "rsc.c" is used for an authoritative recomputation.

MatLab ${ }^{\mathrm{TM}}$ scripts to aid testing of this software are included.

The software and supporting data and scripts are in the subdirectory named "ResponseSpectra". 


\section{Self-noise Computation via MatLab ${ }^{\mathrm{TM}}$}

There are nearly as many methods and variants of methods as practitioners (e.g., Press et $a l .$, 1992) for computing power spectral density (PSD) and its equivalent, the root-mean-square (rms) spectrum, the square root of the PSD spectrum. For use by the ANSS (ANSS TIC, 2002, as amended) we have selected a single, explicitly defined method of performing these computations, encoding and illustrating this technique as a MatLab ${ }^{\mathrm{TM}}$ script. (This script and the others in this software release were developed in MatLab ${ }^{\mathrm{TM}}$ version 7.1.0.183 (R14) service pack 3 and may require modifications for other versions of that system.) Users are encouraged to use this script directly for computing self noise in appropriate circumstances, obviously substituting their own data.

The ANSS TIC will also specify that all dynamic-range and self-noise illustrations be uniformly provided by vendors in terms of bin-wise rms values and graphics (that is, in units of $\left.\left(\mathrm{cm} / \mathrm{s}^{2}\right) / \sqrt{ } \mathrm{Hz}\right)$ and that this computation shall be that encoded here. Such values should not be provided as PSD or as partial-octave renditions of the rms spectrum. While this script, "ANSS_noise_rms_rev4.m", does compute the PSD and partial octaves, only the bin-wise rms spectrum is to be used in evaluating instruments.

This MatLab ${ }^{\mathrm{TM}}$ script is appropriate whenever one has a long record of noise (ideally hours long at 200 samples per second), from a shorted-input recorder ("DAU"). Similarly, when the whole system's ("DAS's" = DAU + sensors) self noise is known to be well below the ambient seismic noise at the recording site and also below the DAU's self noise, the self noise of the sensor can be reliably separated from the DAS self noise. No atypical signals are to be included in such records (e.g., earthquakes, vehicles, sonic booms, EMF interference). An equivalent method for computing the rms spectrum via two- and three-instrument simultaneous records will be provided at a later date to be used with sensors about as sensitive as ambient seismic noise at the test site.

The software and supporting data and scripts for this rms computation are in the subdirectory named "SelfNoise".

\section{References Cited}

ANSS TIC, 2002, Technical Guidelines for the Implementation of the Advanced National Seismic System, U.S. Geol. Surv. Open File Rep., 02-92, 92 pp.

Converse, A. M., and Brady, A. G., 1992, BAP: basic strong-motion accelerogram processing software; version 1.0, U.S. Geol. Surv. Open File Rep., 92-296A, 177 pp.

Nigam, N. C., and Jennings, P. C., 1969, Calculation of response spectra from strong-motion earthquake records, Bull. Seis. Soc. Am., 59, 909-922.

Press, W. H., Flannery, B. P., Teukolsky, W. T., and Vetterling, W. T., 1992, Numerical Recipes in $C$, Cambridge Univ. Press, New York. 